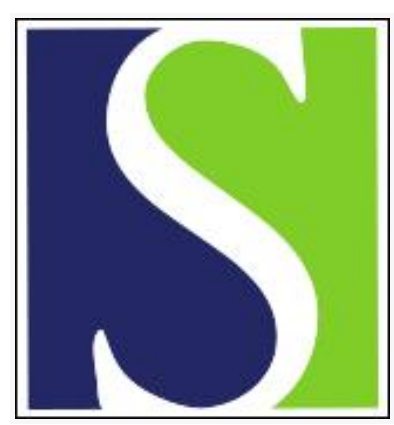

Scand J Work Environ Health 1991;17(5):337-346

https://doi.org/10.5271/sjweh.1700

Issue date: Oct 1991

Back disorders and nonneutral trunk postures of automobile assembly workers.

by Punnett L, Fine LJ, Keyserling WM, Herrin GD, Chaffin DB

Affiliation: Center for Ergonomics, University of Michigan, Ann Arbor.

This article in PubMed: www.ncbi.nlm.nih.gov/pubmed/1835131

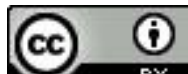




\title{
Back disorders and nonneutral trunk postures of automobile assembly workers
}

\author{
by Laura Punnett, ScD, ${ }^{1,2}$ Lawrence J Fine, MD, ${ }^{1,3} \mathrm{~W}$ Monroe Keyserling, PhD, ${ }^{1}$ \\ Gary D Herrin, PhD, ${ }^{1}$ Don B Chaffin, $\mathrm{PhD}^{1}$
}

\begin{abstract}
PUNNETT L, FINE LJ, KEYSERLING WM, HERRIN GD, CHAFFIN DB. Back disorders and nonneutral trunk postures of automobile assembly workers. Scand $J$ Work Environ Health 1991;17:33746. A case-referent study was conducted in an automobile assembly plant to evaluate the health effect of trunk postures, such as bending and twisting, that deviate from anatomically neutral. Cases of back disorders were all those of workers who reported back pain to the medical department in a ten-month period and met the severity criteria of an interview. The referents were randomly selected workers free of back pain according to medical department records, an interview, and an examination. For each of the final 95 cases and 124 referents, the job was analyzed for postural and lifting requirements with a video recording and software analysis system by analysts blinded to the case/referent status. Back disorders were associated with mild trunk flexion [odds ratio (OR) 4.9, $95 \%$ confidence interval $(95 \% \mathrm{CI})$ 1.4-17.4], severe trunk flexion (OR 5.7, $95 \%$ CI 1.6-20.4), and trunk twist or lateral bend (OR 5.9, $95 \% \mathrm{CI} 1.6-21.4)$. The risk increased with exposure to multiple postures and increasing duration of exposure.
\end{abstract}

Key terms: back pain, ergonomics, job analysis methods, musculoskeletal disorders, postural analysis, repetitive work, video recording.

The most studied occupational risk factor for back pain is the manual lifting of moderate to heavy loads $(1-8)$. In the United States, the risks associated with lifting activities were considered well enough established by 1981 that the National Institute for Occupational Safety and Health (NIOSH) issued the Work Practices Guide for Manual Lifting (9). Other risk factors for back disorders in the work environment have been cited (1-8), but the epidemiologic evidence is still surprisingly sparse for most of them when the frequency and cost of this problem in modern industry is considered $(9-11)$.

In particular, most occupational ergonomists consider postures that deviate from anatomically neutral to be physical stressors that should be minimized by correct job, tool, and workstation design (12). However, information is limited regarding the risk of injury imposed on the back by nonneutral trunk postures such as bending forward or sideways, especially when little or no load is held in the hands. A few studies have demonstrated short-term effects (fatigue, pain, increased muscular activity, or increased intradiscal pres-

\footnotetext{
1 Center for Ergonomics, The University of Michigan, Ann Arbor, Michigan, United States.

2 Currently with the Department of Work Environment, University of Lowell, Lowell, Massachusetts, United States.

3 Currently with the Division of Surveillance, Hazard Evaluation and Field Studies, National Institute for Occupational Safety and Health, Cincinnati, Ohio, United States.
}

Reprint requests to: Dr L Punnett, Department of Work Environment, University of Lowell, One University Avenue, Lowell, MA 01854, USA. sure) from unloaded static trunk postures such as forward flexion, twisting, and lateral bending (13-16).

The epidemiologic data are even more limited regarding the relationship between these "nonneutral" trunk postures and either acute or chronic disorders of the back. Some investigators have found exposures to these postures to be reported more often by backpain sufferers than by pain-free individuals $(1,2,6$, 17,18 ), but these associations have not necessarily been adequately controlled for potential confounding, especially where heavy lifting is also performed. In most cases, exposure to postural stress has been determined by self-reports or assumed to be constant across job title. Other studies have failed to find any association with bending or rotation of the trunk when no weight was held in the hands $(4,19-21)$.

The goal of this study, therefore, was to investigate the potential relationship between the use of nonneutral trunk postures at work and the risk of musculoskeletal back disorders reported to an industrial medical department. The specific postural and biomechanical demands of jobs performed in an automobile assembly plant were evaluated and compared for workers with and without back disorders.

\section{Subjects and methods}

\section{Subjects}

A case-referent study was conducted among the active employees of an automobile assembly plant during 1984 and 1985. All of the workers employed in the four major production departments (body, paint, trim, and 
chassis) were eligible to participate. These four departments employed about 1335 workers (monthly average during the study period) and accounted for the majority of the work force in the assembly plant.

Cases were defined as those workers who filed new reports of back disorders at the plant medical department between 10 June 1984 and 4 April 1985, inclusive, and who had symptoms of back disorders in an interview and an examination, with or without physical findings. All workers who reported to the medical department for any back condition during the study period were identified, and those making repeat visits for previous complaints were excluded.

The referents were defined as those workers who did not report any back disorders to the medical department during the study period and who had no symptoms or signs of back disorders in an interview and an examination. The rosters of the four production departments were obtained at the beginning of the data collection period. Names were selected at random, and the subjects were then excluded if a medical report had been filed for any back, neck, or shoulder disorder within the $90 \mathrm{~d}$ preceding the interview date or prospectively from the start of data collection, whichever was earlier. (The reason for excluding neck and shoulder injuries was that the referents were also intended to serve as the basis for comparison in a parallel study of shoulder disorders. In addition, some ergonomic risk factors for neck and shoulder disorders might have been highly correlated with those under study for back disorders.)

Between 11 June 1984 and 4 April 1985, a total of 144 potential cases was identified, and an additional 310 workers were selected as potential referents. Of these, 377 workers $(84 \%)$ were interviewed and examined, comprising 259 potential referents and 118 potential back cases. The proportions of workers interviewed were almost identical ( $84 \%$ referents, $82 \%$ cases).

Ninety-five $(81 \%)$ of the 118 workers who reported back pain to the medical department and were interviewed also met the study criteria for pain in an interview and were defined as cases. Forty-five of these $(47 \%)$ had one or more positive findings in a physical examination of the back. Jobs were identified (according to the aforementioned criteria) and analyzed for all 95 cases.

Among the 259 workers interviewed as potential referents, $135(52 \%)$ reported being free of back, neck, or shoulder pain. Ten of these experienced back pain in the physical examination and were subsequently excluded. The job of one referent could not be analyzed. Thus 124 workers met the criteria for inclusion as referents.

Of the 219 final study subjects, 215 were men. They ranged in age from 29 to 64 years. The median length of employment in the plant was 11.8 years, average 10.6 (SD 8.0) years; $69 \%$ had been in their current job for less than five years.

\section{Interview and examination}

Each study subject was interviewed with a standardized questionnaire that had previously been tested in a pilot study. The questionnaire included items on demographics, work history, medical history, and nonoccupational activities. The cases and referents were interviewed concurrently throughout the study period.

Back pain was defined in the interview as a history of at least three separate episodes, or at least one episode lasting for at least one week, within the year preceding the date of the interview. This finding determined the inclusion of potential cases and the exclusion of potential referents. It also prompted the administration of a supplementary questionnaire to obtain additional information about pain characteristics and the jobs and tasks associated with the first onset and aggravation of back pain.

After the interview, each worker received a screening examination consisting of a series of 26 active, passive, and resisted motions that concentrated on the ranges of motion of the back, neck, and shoulders (22). This examination evaluated the status of the inert tissue of the joints and the muscle/tendon groups about the joints. When a worker reported pain for any component of the examination, he or she was asked to rate it on a scale from 1 (very mild) to 8 (very severe).

\section{Ergonomic job analysis}

For each worker interviewed, one job was selected for videotaping and analysis. For the cases, the preferred job for analysis was the one held at the time of first onset of the current episode, if that job was still performed in the plant. However, in automobile assembly, annual model changes frequently result in some changes in job content and physical demands. Therefore this option was not possible for $14(15 \%)$ of the final cases. In such situations, the "study job" was defined as a job that the worker had experienced as aggravating the pain, if it was still performed in the plant, or, otherwise, the current job, if the worker still had pain in that job. For all the referents, the current job was videotaped.

A few subjects refused to be videotaped after the interview, no longer performed the identified "study job," or could not subsequently be located in the plant. (See "Use of Proxy Subjects" in the Results section.) In that event, permission to videotape was requested from another worker performing the "study job" of the index subject.

Most jobs performed in automobile assembly are machine-paced and highly repetitive; the speed of the line throughout this plant was approximately 60 units per hour. Work cycles were observed to vary relatively little over the course of the workday. The cycles to be analyzed were selected to avoid any obvious interruptions or unusual events. Thus the characterization of physical demands during one selected cycle was assumed to describe the majority of the ergonomic 
stressors to which a subject was exposed during a typical workday.

The postural analysis system involved reviewing a videotape of the work cycle in "simulated real time" and keying in postural changes as observed (23). The software system performed the time-keeping functions and provided a continuous record of the trunk postures used during the work cycle. Several summary statistics were generated for each job analyzed (ie, the total time spent in each posture, in seconds and as a percentage of the work cycle, and the number of times per cycle that the back entered the specified posture). The posture classifications were defined as neutral ( $<20$ degrees of bending or twisting in any direction), mild forward flexion (21-45 degrees), severe forward flexion ( $>45$ degrees), and lateral bending or twisting ( $>20$ degrees) (figure 1). Fewer than 10 workers each were required to work in other postures [standing with the trunk extended (bent backwards), sitting with the back flexed or twisted, kneeling, or lying flat], and therefore the effect of these postures could not be evaluated.

In each job, the peak biomechanical forces on the spine were analyzed for up to nine postures where a load weighing at least $44.5 \mathrm{~N}$ (10 pounds) was held in the hands. The peak reactive torques for three back muscle groups and compressive forces acting at the L5/S1 spinal disc were estimated according to a threedimensional biomechanical strength model (24). In the jobs that did not require the lifting of at least $44.5 \mathrm{~N}$ the peak biomechanical forces were estimated for the effect of body weight on the posture that deviated the most severely from neutral.

\section{Statistical methods}

The cases and referents were compared with respect to their exposures to both nonneutral postures and biomechanical forces. The exposure data were treated both as dichotomous (yes/no) and as continuous variables. All the analyses were performed with the SAS (statistical analysis system) software package (25).

The frequency of each exposure, as a dichotomous variable, was compared between the cases and referents from computations of the odds ratio (OR), interpreted as the incidence density ratio, and its approximate $95 \%$ confidence interval $(95 \% \mathrm{CI})(26)$. The Student t-test was used to the compare continuous variables, if they were normally distributed, with equal or unequal variances as indicated by the $F$ statistic (27); the Wilcoxon rank sum test for nonparametric comparisons was used for continuous variables with nonGaussian distributions (28).

In order to evaluate and control for potential confounding and effect modification, we obtained information on gender, age, length of employment, recreational activity, medical history, and the maximum weight lifted in the study job. The distributions of the cases and referents were compared across strata of each third factor in turn. The stratum-specific odds ratios were tested for homogeneity (29), and, if appropriate, the Mantel-Haenszel estimator of the common or pooled odds ratio was calculated along with the corresponding $95 \% \mathrm{CI}(30)$.

The duration of each posture was also trichotomized (no use, use up to $10 \%$ of the work cycle, use for more than $10 \%$ of the cycle time), and odds ratios were calculated for the second and third of these tertiles compared with the first. Chi-square statistics on one de-
NEUTRAL

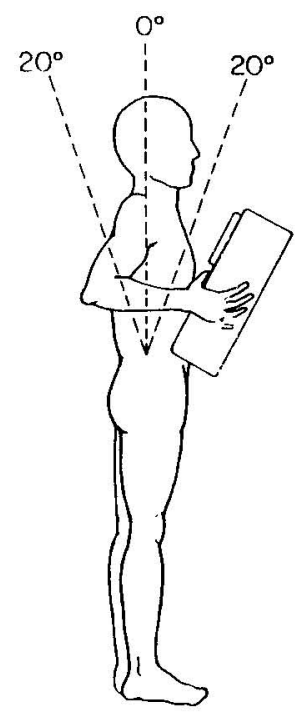

MILD

FLEXION

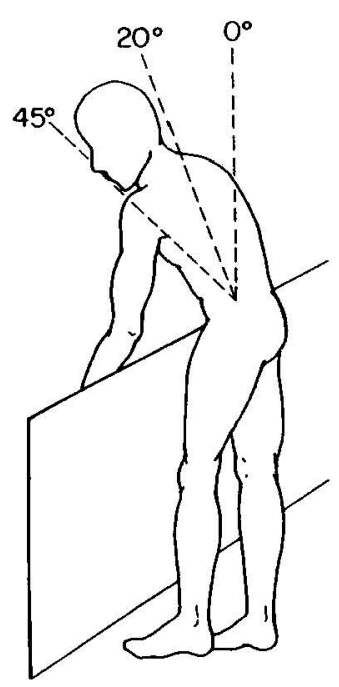

SEVERE

FLEXION
LATERAL BEND
OR ROTATION
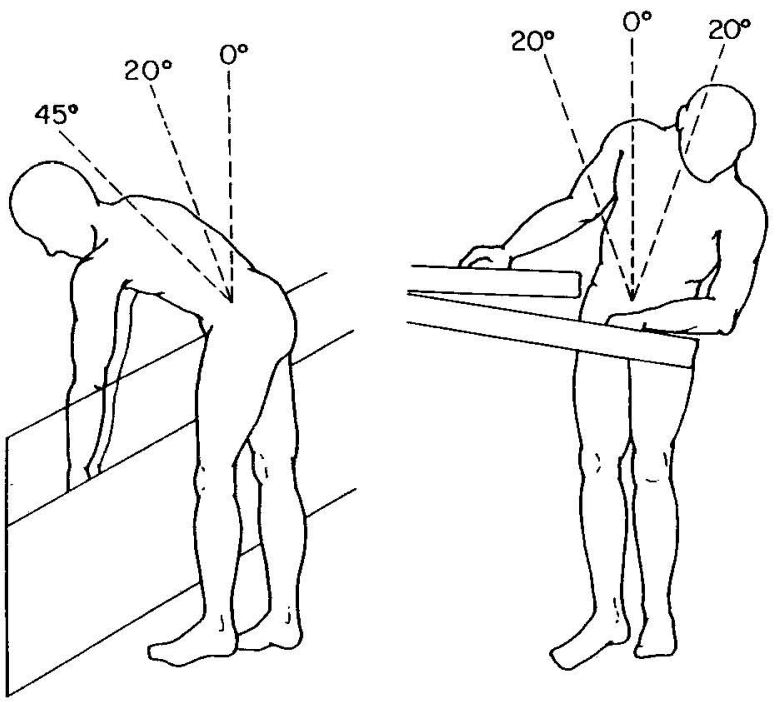

Figure 1. Standard trunk posture classifications. 
gree of freedom (31) were used to test for linear trend in the odds of being a case with increasing postural exposure.

Multivariate logistic regression analysis was used to estimate the odds ratio for back disorders as a function of workplace postural stress, other independent variables being simultaneously controlled for. Because of the covariance among the times spent in the three trunk postures, the exposure variable used was the sum of these durations (ie, the total proportion of the work cycle in any nonneutral posture). With only a few subjects with zero exposure to postural stress, this continuous exposure variable would be more sensitive to changes in relative proportions of cases and would also permit a measure of exposure-response.

Tests of statistical significance and confidence intervals were calculated from the maximum likelihood estimates of the coefficients and their standard errors. The contribution of adding each new term to a model in a nested series was evaluated by the likelihood ratio test, which is twice the difference of the maximized log likelihood statistics for the models with and without the new term, distributed approximately as a chisquare statistic (29).

\section{Results}

Many of the study jobs involved substantial postural loading of the trunk muscles. There were 185 subjects $(84 \%)$ who worked with the trunk in mild flexion for any amount of time during the workday, 112 subjects $(51 \%)$ who were exposed to severe trunk flexion for any length of time, and 98 subjects $(45 \%)$ who were exposed to work with the trunk bent laterally or twisted. Only 20 workers ( 3 cases and 17 referents) could be classified as "unexposed" on the basis of maintaining the trunk in a neutral posture during the entire job cycle.

Some of the study jobs had highly static postural demands. The subjects were found to maintain mild flexion postures for up to $80 \%$ of the work cycle, severe flexion up to a maximum duration of $74 \%$ of the work cycle, and twist or lateral bend up to $35 \%$ of the cycle. The back cases, compared with the referents, spent a significantly greater proportion of the work cycle, on the average, with the trunk in both mild flexion (12.8 versus $9.7 \%$, Wilcoxon $P=0.04)$ and severe flexion ( 7.4 versus $4.1 \%$, Wilcoxon $P=0.02$ ).

Table 1. Associations between back disorders and trunk postures.

\begin{tabular}{lcc}
\hline Trunk posture (yes/no) & $\begin{array}{c}\text { Odds } \\
\text { ratio }\end{array}$ & $\begin{array}{c}95 \% \text { confidence } \\
\text { interval }\end{array}$ \\
\hline Mild flexion & 4.9 & $1.4-17.4$ \\
Severe flexion & 5.7 & $1.6-20.4$ \\
Twist or lateral bending & 5.9 & $1.6-21.4$ \\
\hline
\end{tabular}

a Exposure to specified trunk posture during a regular work cycle of the study job, compared with no exposure to any nonneutral posture. The exposures are not mutually exclusive. See the text and figure 1 for the posture categories.
In other study jobs, the postural stress to the back was more dynamic than static in nature. The frequency of postural changes ranged as high as 18.5 trunk movements per minute of the work cycle. The cases changed trunk posture in any direction more frequently than the referents ( 8.2 versus 6.4 movements per minute, Wilcoxon $P=0.03$ ). These changes included more frequent mild flexion ( 2.3 versus 1.8 per minute), more frequent severe flexion ( 0.9 versus 0.6 per minute), and more frequent trunk twisting or lateral bending $(0.8$ versus 0.6 per minute).

The cases were roughly five times more likely than the referents to work with the trunk in mild flexion for any length of time and about six times more likely to work with the trunk either in severe flexion or twisted or bent sideways (table 1).

The cases were subsequently divided into those with and without findings in the physical examination, and odds ratios were calculated for each subgroup of cases in comparison with the referents. There was little difference in the exposure prevalence between the two subgroups of cases (for each posture, Fisher's exact $P=0.14)$. However, since all three unexposed cases had negative physical examinations of the back, the associations were even stronger in the stratum with positive findings in the physical examination.

The distribution of exposure time for each posture was divided into the following three categories: zero elapsed time, less than $10 \%$ of the work cycle, and $10 \%$ or more. Odds ratios for cases versus referents were calculated for the second and third categories of exposure duration, compared with no exposure. The magnitude of the odds ratios increased with increasing length of exposure to both mild and severe trunk flexion (table 2).

Most of the subjects were exposed to more than one nonneutral trunk posture during the work cycle. The separate effect of each identified posture (mild flexion, severe flexion, or twisting/lateral bending) was estimated among those subjects who used only that posture. Exposure to either mild flexion or twisting alone had an odds ratio of about 2.3 , based on small numbers of subjects. Only three cases and one referent were exposed exclusively to severe flexion; the odds ratio for this posture alone was 17.0 but highly unstable because of the sparse data.

The subjects exposed to more than one posture were used to estimate the effects of each posture combination observed in the workplace. Exposure to both mild flexion and twisting was associated with the greatest increase in risk (table 3). However, the estimate for each separate combination was based on a relatively small number of subjects.

\section{Stratified analyses}

The cases were somewhat younger on the average (referents 41.4 years, cases 38.6 years) and had been employed for slightly less time (mean 3.8 years) than 
the referents (mean 5.1 years) in their current jobs. The odds ratios for each of the three postures (dichotomized) in the top half of table 1 were recalculated after stratification in turn by decade of age and by decade of length of employment, both in the plant and in the current job. For both age and years in the current job, all of the Mantel-Haenszel (M-H) odds ratios for the effect of postural stress were slightly higher than the corresponding crude estimates. For years worked in the plant, there was no change from the crude odds ratios to the $\mathrm{M}-\mathrm{H}$ estimates, but the confidence intervals were slightly narrower.

Sixty-eight subjects reported at least one acute back injury prior to the reported onset date of the current back pain. The odds ratios for workers without prior injuries were slightly lower than the crude estimates. The odds ratios for workers with prior injuries could not be estimated because there were no unexposed cases.

Fourteen cases and nine referents reported a history of rheumatoid arthritis, gout, or ruptured spinal disc in the interview. Nine of these workers also reported the ruptured disc as a previous back injury. No subject reported ankylosing spondylitis. The odds ratios for postural stress after the exclusion of these 23 workers were slightly lower than the crude estimates.

Fifty-one $(54 \%)$ cases and $62(50 \%)$ referents reported engaging weekly in one or more hobbies, sports, or second jobs. The distributions of cases and referents did not vary among the reported types of activities (racquet or ball sports, other sports, music, or household activities). Among the workers participating in these activities, the cases did so for an average of $7.0 \mathrm{~h}$ and the referents for $9.4 \mathrm{~h}$ per week (Wilcoxon $P=0.34)$. Only $16(17 \%)$ cases and $18(15 \%)$ referents regularly participated in baseball, golf, or bowling (OR 1.2, $95 \% \mathrm{CI} 0.5-2.6$ ). The effect of trunk posture was higher among the workers who did not engage in any outside activity ( $O R \geq 9.3$ for each posture).

Twenty-one $(22 \%)$ cases and $16(13 \%)$ referents were observed to lift parts or tools weighing at least $44.5 \mathrm{~N}$. Among these 37 workers, the estimated mean peak compression at the L5/S1 disc was low relative to the NIOSH guideline (9) for both the cases $(1938 \mathrm{~N})$ and the referents $(2437 \mathrm{~N})(\mathrm{P}=0.16)$. Among all 219 workers, the estimated peak low-back compressive forces were virtually the same between the cases (mean $1915 \mathrm{~N}$ ) and the referents (mean $1871 \mathrm{~N}$ ). The M-H odds ratios for postural stress were slightly lower after control for lifting, and the confidence intervals were slightly narrower.

\section{Logistic regression analysis}

The logistic model was fitted initially to the primary exposure variable, the total proportion of the work cycle maintained in any nonneutral posture. The univariate model was highly statistically significant by the likelihood ratio test $(P=0.01)$. The odds ratio representing an increase from 0 to $100 \%$ of the work cycle in any nonneutral posture was $7.4(95 \% \mathrm{CI}$ 1.5-35.4). For comparison with the effects calculated from the trichotomized exposure variable, the odds ratios for 10,30 , and $50 \%$ of the work cycle exposed (compared with zero exposure) were 1.2, 1.8, and 2.7, respectively. (The discrepancy was due to the fact that the distribution of the exposure data was skewed to the right rather than Gaussian.)

The additional independent variables considered for inclusion in the model were gender, age (years), years in the plant, years in current job, history of back injury or ruptured spinal disc (yes/no), history of systemic disease (yes/no), type of weekly recreational activity, hours per week in hobbies or sports, lifting or holding of a part weighing at least $44.5 \mathrm{~N}$ (yes/no), and estimated peak low-back compressive force (in newtons).

Both forward and backward stepwise regression procedures were used to determine which variables should be added to the univariate model, the covariances among them being taken into account. None of the additional variables resulted in any marked change in either the point estimate or the confidence interval for the effect of the primary exposure variable for postural stress.

Table 2. Trends in risk of back disorders with duration of exposure to postural stress.

\begin{tabular}{|c|c|c|}
\hline Trunk posture ${ }^{a}$ & $\begin{array}{l}\text { Odds } \\
\text { ratio }\end{array}$ & P-value ${ }^{b}$ \\
\hline \multicolumn{3}{|l|}{ Any posture } \\
\hline $\begin{array}{l}0-10 \% \text { of cycle time } \\
\geq 10 \% \text { of cycle time }\end{array}$ & $\begin{array}{l}3.8 \\
5.5\end{array}$ & 0.006 \\
\hline \multicolumn{3}{|l|}{ Mild flexion } \\
\hline $\begin{array}{l}0-10 \% \text { of cycle time } \\
\geq 10 \% \text { of cycle time }\end{array}$ & $\begin{array}{l}4.2 \\
6.1\end{array}$ & 0.014 \\
\hline \multicolumn{3}{|l|}{ Severe flexion } \\
\hline $\begin{array}{l}0-10 \% \text { of cycle time } \\
\geq 10 \% \text { of cycle time }\end{array}$ & $\begin{array}{l}4.4 \\
8.9\end{array}$ & 0.003 \\
\hline \multicolumn{3}{|l|}{ Twist or lateral bending } \\
\hline $\begin{array}{l}0-10 \% \text { of cycle time } \\
\geq 10 \% \text { of cycle time }\end{array}$ & $\begin{array}{l}6.6 \\
3.8\end{array}$ & 0.42 \\
\hline
\end{tabular}

Table 3. Associations between back disorders and trunk posture combinations.

\begin{tabular}{lcc}
\hline Trunk posture (yes/no) & $\begin{array}{c}\text { Odds } \\
\text { ratio }\end{array}$ & $\begin{array}{c}95 \% \text { confidence } \\
\text { interval }\end{array}$ \\
\hline Mild and severe flexion & 5.1 & $1.4-19.2$ \\
Mild flexion and twist & 7.4 & $1.8-29.4$ \\
All three postures & 5.9 & $1.5-22.7$ \\
\hline
\end{tabular}

a Compared with no exposure to any nonneutral posture. 
Table 4. Final logistic regression model of back disorders.

\begin{tabular}{|c|c|c|}
\hline Independent variable & $\begin{array}{l}\text { Odds } \\
\text { ratio }\end{array}$ & $\begin{array}{c}95 \% \text { confidence } \\
\text { interval }\end{array}$ \\
\hline $\begin{array}{l}\text { Time nonneutral } \\
\text { Lift } 44.5 \mathrm{~N}^{\mathrm{b}} \\
\text { Age (years) } \\
\text { Back injury }{ }^{\mathrm{b}, \mathrm{c}} \\
\text { Intercept }\end{array}$ & $\begin{array}{l}8.09 \\
2.16 \\
0.96 \\
2.37\end{array}$ & $\begin{array}{l}1.5-44.0 \\
1.0-4.7 \\
0.9-1.0 \\
1.3-4.3\end{array}$ \\
\hline
\end{tabular}

-2 log likelihood (intercept only) $=299.75$

$-2 \log$ likelihood (model) $=275.97$

Model chi-square on 4 degrees of freedom $=23.78(P<0.001)$

a Postural stress in the study job, as the proportion of work cycle (sum of durations of mild flexion, severe flexion, and twisting).

b Coded $0=$ no, $1=$ yes.

c History of back injury or ruptured spinal disk prior to first onset of pain.

The "final model" included history of ruptured disc or acute back injury, lifting $44.5 \mathrm{~N}$, and age (only marginally significant) in addition to total duration of exposure to any nonneutral posture (table 4). The odds ratio for the effect of the duration of exposure was slightly greater than that estimated from the univariate model. The effect of postural stress (extrapolated to $100 \%$ of the work cycle) on the risk of back disorders was almost four times greater than the effect of lifting $44.5 \mathrm{~N}$ at least once per minute throughout the workday.

\section{Use of proxy subjects}

Eighty-three ( $38 \%$ ) of the 219 workers could not be videotaped in their own jobs, and proxy or substitute workers were videotaped performing the jobs that the study subjects had designated in the interview. (See "Ergonomic Job Analysis" in the Methods section.) This was true for 59 cases $(62 \%)$ compared with 24 referents $(19 \%)$. The difference in proportions probably occurred because the cases were asked in the interview to name the jobs associated with first onset of pain (which were not always their current jobs) and because the cases were more likely than the referents to change jobs after developing back pain.

The use of exposure data obtained from a worker other than the study subject was considered to be a potential source of misclassification. The magnitude of the resultant bias was estimated in the analysis. Stratification on the basis of whether or not another worker had been substituted in the job analysis showed that the risks for each posture were greater among the group filmed in their own jobs (table 5). These odds ratios could not be accurately estimated because of a zero cell (no unexposed cases in this stratum), but the pooled estimate for each trunk posture and posture combination was approximately twice the corresponding crude estimate. When an indicator variable for job analysis of a proxy subject was added to the logistic regression model, it was strongly negative $(P<0.0001)$, and the coefficient for the main effect of posture was somewhat larger (OR 9.8 for $100 \%$ exposure).

\section{Discussion}

The results of this case-referent study demonstrated a strong and consistent relationship between occupational exposure to nonneutral trunk postures and musculoskeletal disorders of the back. Only 20 subjects in this population were unexposed to all of the nonneutral postures studied. Nevertheless, a strong increasing trend in risk was observed with both intensity of exposure and with duration of exposure. In particular, the risk from trunk flexion increased both with the duration of exposure and with the degree of flexion from "mild" to "severe." The lack of exposure-response trend for duration of lateral bend or twist was probably due to the small number of subjects with exposure lasting more than $10 \%$ of the work cycle. Exposure to two or three nonneutral postures in the regular work cycle was found to involve a higher risk than exposure to only one posture.

Low-back pain is a nonspecific disorder with a very high prevalence and incidence $(1-3,8-11,32)$. It is intermittent and episodic in nature, with recurrence rates as high as $85 \%$ in certain age groups. Back pain is highly variable in its time course and severity. Most episodes resolve relatively quickly, while a small number result in long-term disability. No standardized definition of disease exists (34). Diagnostic evaluations are of limited usefulness in that at least $50 \%$ of low-back pain symptomatology can never be attributed to a

Table 5. Associations between back disorders and trunk postures, stratified by use of substitute workers in job analyse. (M-H = Mantel-Haenszel)

\begin{tabular}{|c|c|c|c|c|c|}
\hline \multirow{3}{*}{ Trunk posture } & \multicolumn{3}{|c|}{ Substitute workers } & \multicolumn{2}{|c|}{$\mathrm{M} \cdot \mathrm{H}$ estimates } \\
\hline & \multicolumn{2}{|r|}{ Yes } & \multirow[b]{2}{*}{$\mathrm{No}^{\mathrm{b}}$} & \multirow{2}{*}{$\begin{array}{l}\text { Odds } \\
\text { ratio }\end{array}$} & \multirow{2}{*}{$\begin{array}{c}95 \% \text { confidence } \\
\text { interval }\end{array}$} \\
\hline & $\begin{array}{l}\text { Odds } \\
\text { ratio }\end{array}$ & $\begin{array}{c}95 \% \text { confidence } \\
\text { interval }\end{array}$ & & & \\
\hline $\begin{array}{l}\text { Mild flexion } \\
\text { Severe flexion } \\
\text { Twist/lateral bending }\end{array}$ & $\begin{array}{l}5.1 \\
5.0 \\
5.7\end{array}$ & $\begin{array}{l}1.1-23.6 \\
1.0-24.4 \\
1.1-28.8\end{array}$ & $\begin{array}{l}10.5 \\
12.9 \\
12.3\end{array}$ & $\begin{array}{r}9.9 \\
10.4 \\
11.5\end{array}$ & $\begin{array}{l}2.3-42.2 \\
2.4-44.7 \\
2.6-51.3\end{array}$ \\
\hline
\end{tabular}

a Compared with no exposure to any nonneutral posture.

b No cases unexposed to any posture; odds ratios undefined, estimated here using 0.5 correction in each cell. 
specific structural finding (33). Findings in physical examinations appear to be correlated with recent and severe episodes, rather than with lifetime history. For these reasons, back pain is actually a continuous outcome rather than a dichotomous one, and the identification of onset or "incidence" of a back disorder is problematic, both conceptually and operationally. Thus both cases and referents are difficult to define for an epidemiologic study. (Epidemiologic studies of most musculoskeletal disorders must address these problems, which can only be avoided through a prospective investigation with very frequent monitoring of symptoms and signs for all the study subjects.)

In this investigation, cases were defined as those workers who filed new reports of back disorders at the plant medical department during the study period and who had findings of back disorders that met predefined criteria in the interview and examination. The goal of these criteria was to identify those workers with a complaint of minimum severity that might be considered to be of clinical significance, and with recent onset, to minimize possible recall bias, and to concentrate on factors related more to the incidence than to the prevalence of back pain. Cases were included regardless of the findings of the physical examination. However, analysis of the subset with physical findings showed stronger associations with posture. Case selection was not restricted to back pain deemed compensable by the company so that the risk factors for pain could be studied rather than the factors predictive of the ability to obtain compensation (32).

The referents in this study were defined as those workers who did not report any back disorders to the medical department during the study period and who had no symptoms or signs of back disorders in an interview and examination. The goal of these criteria was to identify individuals with no back pain of more than minimal severity in the present or recent past. (An alternative approach might have utilized "case-base" sampling, for increased efficiency in the study of multiple outcome events.)

In the original group of 214 randomly selected workers who were intended to serve as referents, $134(63 \%)$ had symptoms or signs of back disorders but had not reported these problems recently to the plant medical department. This finding is consistent with that of other studies of musculoskeletal disorders, in which more cases have been identified through the use of interviews and physical examinations than through the use of company records alone (35). Further studies are required to evaluate the relative importance of clinical, socioeconomic, and psychological factors in determining whether or not, and when, a worker reports a condition to the medical department. Without being able to explore this question in the present study, we chose to use the medical reporting system as the primary basis for the case definition because it was possible to observe the moment in which an individual became a case. This delineation would be almost impos- sible for a definition not based on the reporting of pain, where the identification of the appropriate job for exposure characterization would be even more troublesome. In addition, we wished to define cases and referents so as to maximize the contrast between their experiences of back pain, in order to maximize the power of this investigation to identify risk factors for more recent, severe, and persistent back disorders. However, a limitation of this approach is that the decision to report a chronic disorder does not represent a standardized point in the disease progression among all cases.

Because exposures could not be measured at the moment of first onset (incidence) of back pain, it is possible that the risk factors identified were a mixture of those that aggravated existing disorders and those associated with etiology. There is no substantive reason to believe that factors predictive of onset are likely to be very different from those that aggravate preexisting back conditions. However, to the extent that these factors are different, this study would have had limited ability to distinguish between the two groups of stressors.

It seems unlikely that the positive associations reported in this investigation were artifacts of selection or information bias. The participation rates of the back cases and referents were similar and relatively high $(82-84 \%)$. The data on postural and force job requirements were collected and analyzed objectively by members of the research team who were blinded as to the case-referent status of the study subjects.

The possibility of "healthy worker selection" out of this study population should be considered. The cases and referents were selected from actively employed individuals in that it was not possible to define and study a full cohort of individuals at the beginning of employment. Approximately half of the cases had experienced prior incidents of back pain more than six months before the index report; it is possible that other workers who developed back problems during the course of their employment had already left the plant. If self-selection out of employment did not occur randomly with respect to exposure, the associations estimated from this data set could be underestimates of the true values (36). There is some evidence that such a selection effect had occurred in this population in that back pain was not positively associated with either age or length of employment.

Self-selection of workers could also occur out of highly exposed jobs, rather than out of employment altogether. Almost $75 \%$ of the cases reported difficulty in doing their current or past jobs, and about one-third reported that they had voluntarily transferred from previous job assignments because of back pain. We were unable to determine whether these workers had transferred to jobs with markedly different ergonomic exposures than those of the jobs they had held at the time of reported onset. The evaluation of exposure for the cases was based on the jobs 
that they had held at the time of first onset of back pain, in order to reduce this potential selection bias. However, the jobs for 14 cases were no longer performed in the plant, and current or "aggravating" jobs had to be analyzed instead. Any resulting misclassification would be likely to bias the estimates of effect toward the null hypothesis.

Since postures during work could not be observed prior to the cases' first onset of back pain, we have no information about whether workers might have altered their work methods and postures after the onset of pain. Any such changes would very likely have occurred as a result of the subjects' attempts to reduce pain by reducing the intensity or duration of exposure to postural stress. Therefore, if there was any misclassification of exposure, it would again probably have been in the direction of an underestimation of the postural exposures of the cases prior to or at the onset of back pain and thus an underestimation of the magnitude of the associations.

On automobile assembly lines, most jobs are performed by only two workers at any given time. Because of the small number of jobs performed by more than one study subject, it was not possible in this study to examine directly the important question of interindividual variability in work postures. Again, when postural data from one worker are applied to another study subject, any such variability would result in random misclassification of exposure and an underestimation of the true parameters. In this study, the necessity to use postural data from one worker to estimate the exposure of another, for a minority of study subjects, did appear to result in an underestimation of the magnitude of the associations. The odds ratio for each trunk posture, when calculated only for the workers who were filmed performing their own jobs, was more than double the crude estimate.

Some of this difference may reflect the importance of individual anthropometry or work methods, or both, in determining posture in the workplace. Some of it may also have been due to the fact that job content and ergonomic exposures may have changed slightly since the cases' first onset, given the constant state of flux in the automobile assembly process.

This finding is of inherent interest because it demonstrates the importance of characterizing exposure to postural stressors for each subject individually, as well as the possible magnitude of exposure misclassification in studies in which exposure is evaluated only at the level of job title or other group variable.

Nonoccupational risk factors that have been demonstrated or postulated for low-back pain include age, height, weight, acute traumatic spinal injury, certain recreational activities, muscular strength and general physical fitness, smoking, psychosocial characteristics, severe disc degeneration, specific structural radiographic abnormalities (spondylolysis, spondylolisthesis), severe scoliosis, and autoimmune diseases such as ankylosing spondylitis $(32,33)$. Gender does not ap- pear to be a risk factor in the general population (1, $2,8,32$ ).

Data on age, gender, medical history, prior injuries, and sports, hobbies or second jobs were obtained by interview, and their effects were examined. Only two of these variables (a history of ruptured disc or acute back injury and lifting of $44.5 \mathrm{~N}$ ) were significantly associated with back disorders in the multivariate logistic regression. Ruptured spinal disc was included even though it might in some instances represent an acute outcome of the ergonomic risk factors under study, rather than a confounding variable. (Including it in the statistical analysis would therefore reduce the estimated effect of these factors.) None of the additional variables had a substantial effect on either the magnitude or the stability of the estimated odds ratios for postural exposures. Specifically, no effect was found for weekly baseball, golf, and bowling. The negative association observed with recreational activities was judged likely to be due to the self-selection of back pain cases out of participation in sports, rather than to a protective effect.

Height, weight, and smoking history were not recorded in this study. We did not measure muscular strength capacity of the trunk and endurance or psychological attributes. Socioeconomic status was assumed to be relatively invariant within the study population.

Thus, within the limitations of this study, the relationship of back disorders to nonneutral postures was not explained by nonoccupational factors such as gender, age, prior injury, or medical history.

The four occupational risk factors most commonly identified in epidemiologic studies of low-back pain are frequent, sudden or heavy lifting; prolonged sitting; whole-body vibration; and driving motor vehicles $(1-8,32)$. Very few of the workers in this study were observed to be exposed to any of these except lifting. Thus this factor was the only occupational exposure of interest to be characterized in addition to the postural demands.

The additional biomechanical forces imposed by the lifting tasks in the jobs studied appeared to be low to moderate, since most of the workers lifted only small parts or handtools. Detailed biomechanical analyses were performed only if the object lifted involved at least $44.5 \mathrm{~N}$. [In most situations this weight represents a relatively low load by ergonomic criteria, although if lifted with the arms extended it would exceed the strength capability of more than $50 \%$ of the female working population ( 24 chapter 6 ).] Less than $3 \%$ of the analyzed postures resulted in peak compressive forces of $3430 \mathrm{~N}$, the value equivalent to the action limit recommended by NIOSH (9). The highest peak compressive force estimated in these jobs was $5337 \mathrm{~N}$, or below the maximum permissible limit of $6370 \mathrm{~N}$ of NIOSH. (The action limit and the maximum permissible limit represent estimated relative risks of 3 
and 8 , respectively, for back injury among exposed workers.)

Some attention has previously been focused on the effect of lifting in a "stooped" posture [ie, with the trunk flexed forward $(4,6,37)$ or in a posture in which the trunk is twisted or flexed laterally (38-42)]. These outcome measures have been short-term ones, including compressive force estimated or measured at the lumbar spine, metabolic rate, erector spinae electromyographic activity, and voluntary strength capability in specified postures. The hypothesis for each of these measurements concerns the extent to which the posture used at the beginning of the lift increases the strain of a lifting task. These measurements are also applicable to tasks in which only the weight of the body is being supported, but they may not completely describe the effect of postures that are held for longer periods of time.

In any event, estimates derived from biomechanical models would suggest a greater incremental stress on the soft tissues, when moving from "mild" to "severe" flexion, than the small increase in risk demonstrated with the present results. It may be that random misclassification (analyst error in distinguishing the two grades of flexion) diluted the difference between the two estimates. Alternatively, it may be that the mechanism of injury produces a nonlinear exposure-response curve, possibly because of a combination of biomechanical and physiological effects.

There are several competing pathologic mechanisms hypothesized for chronic low-back disorders. They include disc-related factors, such as mechanical failure resulting from compression or poor nutrition (16), and acute or chronic fatigue of the soft tissues, such as that measured as high electrical activity of the spinal muscles (43), deformation of the bone and soft tissues (44-47), or chronic ligament strain (48). One recent study showed that cyclic compressive loading of the lumbar vertebrae, presumably similar in nature to that produced by repetitive flexion in 1-min work cycles, greatly increases the probability of disc failure as compared with a single, sustained exposure to the same magnitude of compressive force (49). Other investigators have argued against the role of spinal disc compression (46) or of muscular insufficiency (13).

The relative importance of these suspected causal mechanisms in the etiology of low-back pain remains unclear $(32,33)$. However, each of these arguments would be at least partially consistent with the present findings, since all of these biomechanical and physiological stresses can be generated by one or more of the trunk postures studied.

The limited prior epidemiologic evidence has been inconclusive regarding the risk from occupational exposure to postures such as forward flexion, lateral bending, and twisting, although methodological difficulties may account for some of the negative results reported. The etiologic fraction of back cases due to the effects of nonneutral trunk postures in this population was estimated to be about $75 \%$. On the basis of these findings, we have recommended to the company and the union that jobs with high postural demands on the trunk be redesigned, when possible, to eliminate such stressors, in addition to the more traditional concern over the high stresses resulting from lifting heavy loads. If future investigations confirm that occupational posture requirements are important causes of chronic back disorders, then another means of preventing this highly prevalent and costly problem could be achieved through anthropometric and postural considerations in the design of tasks, tools, and workplaces.

\section{Acknowledgments}

This research was supported by the Body and Assembly Operations Division, Ford Motor Company. Assistance with the data collection and analysis was provided by Ms MJ Catterall, Mr R Ermak, Mr T Galasso, Ms L Harner, Ms S Lee, Ms P McEachern, Mr D Radson, Mr M Sklar, Mr J Steele, Mr C Woolley, Ms A Wright, and Dr W Butler. The authors gratefully acknowledge the valuable comments of Drs $P$ Buffler, R Hornung, K Steenland, R Luckmann, and D Kriebel.

Earlier versions of this paper were presented at the V International Symposium on Epidemiology in Occupational Health, University of California at Los Angeles, September 1986; and at Musculoskeletal Disorders at Work: An International Conference, University of Surrey, Guildford, England, April 1987.

\section{References}

1. Andersson GBJ. Epidemiologic aspects on low-back pain in industry. Spine 1981;6:53-60.

2. Frymoyer JW, Pope MH, Costanza MC, et al. Epidemiologic studies of low-back pain. Spine 1980;5:419-23.

3. Svensson H-O, Andersson GBJ. Low-back pain in 40to 47-year-old men: work history and work environment factors. Spine 1983;8:272-6.

4. Damkot DK, Pope MH, Lord J, Frymoyer JW. The relationship between work history, work environment and low-back pain in men. Spine 1984;9:395-9.

5. Videman T, Nurminen $T$, Tola $S$, et al. Low-back pain in nurses and some loading factors of work. Spine 1984; 9:400-4.

6. Riihimäki H, Mattsson $\mathrm{T}$, Zitting A, et al. Radiographically detectable degenerative changes of the lumbar spine among concrete reinforcement workers and house painters. Spine 1990;15:114-19.

7. Bigos SJ, Spengler DM, Martin NA, et al. Back injuries in industry: a retrospective study; II. injury factors. Spine 1986;11:246-51.

8. Walsh K, Varnes N, Osmond C, Styles R, Coggon D. Occupational causes of low-back pain. Scand J Work Environ Health 1989;15:54-9.

9. National Institute for Occupational Safety and Health. Work practices guide for manual lifting. Cincinnati, $\mathrm{OH}$ : US Public Health Service, 1981.

10. Webster BS, Snook SH. The cost of compensable low back pain. J Occup Med 1990;32:13-5.

11. Kelsey JL, White AA. Epidemiology and impact of lowback pain. Spine 1980;5:133-42. 
12. Armstrong TJ, Radwin RG, Hansen DJ, Kennedy KW. Repetitive trauma disorders: job evaluation and design. Hum Factors 1986;28:325-36.

13. Jorgensen $K$. Back muscle strength and body weight as limiting factors for work in the standing slightly-stooped position. Scand J Rehabil Med 1970;2:149-53.

14. Boussenna M, Corlett EN, Pheasant ST. The relation between discomfort and postural loading at the joints. Ergonomics 1982;25:315-22.

15. Habes DJ. Use of EMG in a kinesiological study in industry. Appl Ergon 1984;15:297-301.

16. Nachemson A. The load on lumbar disks in different positions of the body. Clin Orthop 1986;45:107-22.

17. Lloyd MH, Gauld S, Soutar CA. Epidemiologic study of back pain in miners and of fice workers. Spine 1986; 11:136-40.

18. Kilböm Å, Lagerlof E, Liew M, Broberg E. An ergonomic study of notified cases of occupational musculoskeletal disease. In: Attwood DA, McCann C, ed. Proceedings of the 1984 international conference on occupational ergonomics. Rexdale (Canada): Human Factors Association of Canada, 1984:256-60.

19. Magora A. Investigation of the relation between low back pain and occupation; 4 . physical requirements: bending, rotation, reaching and sudden maximal effort. Scand J Rehabil Med 1973;5:191-6.

20. Kelsey JL, Githens PB, White AA, et al. An epidemiologic study of lifting and twisting on the job and risk for acute prolapsed lumbar intervertebral disc. J Orthop Res 1984;2:61-6.

21. Gilad I, Kirschenbaum A. About the risks of back pain and work environment. Int J Ind Ergon 1986;1:65-74.

22. Silverstein BA, Fine LJ. Evaluation of upper extremity and low back cumulative trauma disorders: a screening manual. Ann Arbor, MI: Department of Environmental and Industrial Health, School of Public Health, University of Michigan, 1984.

23. Keyserling WM. Postural analysis of the trunk and shoulders in simulated real time. Ergonomics 1986;29: $569-83$.

24. Chaffin DB, Andersson GBJ. Occupational biomechanics. 2nd edition. New York, NY: John Wiley \& Sons, 1991.

25. Statistical Analysis System Institute Inc. SAS user's guides, version 5 edition. Cary, NC: SAS Institute Inc, 1985.

26. Miettinen OS. Estimability and estimation in casereferent studies. Am J Epidemiol 1976;103:226-35.

27. Fleiss JL. Statistical methods for rates and proportions. 2nd edition. New York, NY: John Wiley \& Sons, 1981.

28. Wilcoxon F. Individual comparisons by ranking methods. Biomet Bull 1945;1:80.

29. Breslow NE, Day NE. Statistical methods in cancer research; vol I (The analysis of case-control studies). Lyon: International Agency for Research on Cancer, 1980.

30. Mantel N, Haenszel W. Statistical aspects of the analysis of data from retrospective studies of disease. J Natl Cancer Inst 1959;22:719-48.

31. Mantel N. Chi-square tests with one degree of freedom: extension of the Mantel-Haenszel procedure. J Am Stat Assoc 1963;59:690-700.

32. Kelsey JL. Epidemiology of musculoskeletal disorders. New York, NY: Oxford University Press, 1982:145-67.

33. Frymoyer JW, Howe J. Clinical classification. In: Pope MH, Frymoyer JW, Andersson GBJ, ed. Occupational low back pain. New York, NY: Praeger Publishers, 1984:71-98.

34. Nachemson AL, Andersson GBJ. Classification of lowback pain. Scand J Work Environ Health 1982;8:134-6.

35. Fine LJ, Silverstein BA, Armstrong TJ, Anderson CA, Sugano DS. Detection of cumulative trauma disorders of upper extremities in the workplace. J Occup Med 1986;28:674-8.

36. Monson RR. Occupational epidemiology. 2nd edition. Boca Raton, FL: CRC Press, 1990.

37. Garg A, Herrin GD. Stoop or squat: a biomechanical and metabolic evaluation. AIIE Trans 1979;11:293-302.

38. Garg A, Badger D. Maximum acceptable weights and maximum voluntary isometric strengths for asymmetric lifting. Ergonomics 1986;29:879-92.

39. Kumar S. Physiological responses to weight lifting in different planes. Ergonomics 1980;23:987-93.

40. Warwick D, Novak G, Schultz A, Berkson M. Maximum voluntary strengths of male adults in some lifting, pushing and pulling activities. Ergonomics 1980;23: 49-54.

41. Mital A, Karwowski W, Mazouz A-K, Orsarh E. Prediction of maximum acceptable weight of lift in the horizontal and vertical planes using simulated job dynamic strengths. Am Ind Hyg Assoc J 1986;47:288-92.

42. Schultz AB, Andersson GBJ, Haderspeck K, et al. Analysis and measurement of lumbar trunk loads in tasks involving bends and twists. J Biomech 1982;15:669-75.

43. Pope $M H$, Andersson GBJ, Broman $H$, Svensson $M$, Zetterberg C. Electro-myographic studies of the lumbar trunk musculature during the development of axial torques. J Orthop Res 1986;4:288-97.

44. Farfan HF. Effects of torsion on the intervertebral joints. Can J Surg 1969;12:336-41.

45. Farfan HF, Gracovetsky S. The nature of instability. Spine 1984;9:714-9.

46. Hickey DS, Hukins DWL. Relation between the structure of the annulus fibrosus and the function and failure of the intervertebral disc. Spine 1980;5:106-16.

47. Liu YK, Goel VK, Dejong A, et al. Torsional fatigue of the lumbar intervertebral joints. Spine 1985;10: 894-900.

48. Miller JAA, Schultz AB, Warwick CN, Spencer DL. Mechanical properties of lumbar spine motion segments under large loads. J Biomech 1986;19:79-84.

49. Brinkmann $\mathbf{P}$, Johannleweling $\mathbf{N}$. Mitteilungen aus der Abteilung Biomechanik [Fatigue fracture of human lumbar vertebrae]. Duisburg: Radiologische Klinik und Strahleninstitut, Orthopadische Universitatsklinik Munster, 1986. (Technical report; no 32.)

Received for publication: 7 August 1990 